\title{
Optimal Investment, Consumption, and Life Insurance Choices with Habit Formation and Inflation Risk
}

\author{
Ailing Shi $\mathbb{D}^{1,2}$ Xingyi Li $\mathbb{D}^{3,4}$ and Zhongfei Li $\mathbb{D}^{5,6}$ \\ ${ }^{1}$ School of Mathematics and Statistics, Lanzhou University, Lanzhou 730000, China \\ ${ }^{2}$ School of Education, Lanzhou University of Arts and Science, Lanzhou 730000, China \\ ${ }^{3}$ School of Business, Sun Yat-Sen University, Guangzhou 510275, China \\ ${ }^{4}$ Department of Management, Technology and Economics, ETH Zurich, Zurich, Switzerland \\ ${ }^{5}$ Department of Finance, Business School, Southern University of Science and Technology, Shenzhen 518055, China \\ ${ }^{6}$ College of Big Data Statistics, Guizhou University of Finance and Economics, Guiyang 550025, China
}

Correspondence should be addressed to Xingyi Li; lixy399@mail2.sysu.edu.cn

Received 12 June 2021; Accepted 6 January 2022; Published 27 January 2022

Academic Editor: Chongyang Liu

Copyright (C) 2022 Ailing Shi et al. This is an open access article distributed under the Creative Commons Attribution License, which permits unrestricted use, distribution, and reproduction in any medium, provided the original work is properly cited.

This research studies the optimal consumption, investment, and life insurance choices for a wage earner with habit formation, inflation risk, and mortality risk. The wage earner has access to a risk-free asset, an index bond, and a stock in a financial market. The index bond hedges inflation risk, while life insurance hedges mortality risk. The aim of the wage earner is to maximize the expected utility of consumption, bequest, and terminal wealth, where the utility of consumption comes from the part of the consumption that exceeds a minimum consumption requirement given by the habit level. By using the dynamic programming method, we provide and prove a verification theorem and obtain closed-form expressions for the value function, the optimal life insurance premium rate, and the optimal investment and consumption strategies. Numerical results reveal that habit formation and mortality force change play important roles in the financial behaviors of the wage earner. Especially, the impacts of the expected inflation rate and consumption habit on the optimal strategies are mutual restraint; increasing mortality force raises the demand for life insurance; and the effects of other parameters are also affected by consumption habit and mortality force change.

\section{Introduction}

The problem of investment and consumption has been widely studied in the last few decades. Samuelson [1] formulates and solves a discrete-time problem, corresponding to lifetime planning of consumption and investment decisions. Merton [2] sets up a continuous-time model of consumption and portfolio choices to maximize the expected utility of consumption and terminal wealth. By incorporating the stochastic hyperbolic preferences into the classical model of Merton [2] with constant relative risk aversion (CRRA), Zou et al. [3] studied finite horizon consumption and portfolio decisions of time-inconsistent individuals. Yang et al. [4] studied the properties of the optimal investment-consumption strategies in a finite horizon robust utility maximization framework with different borrowing and lending rates. By considering random endowments in a possibly incomplete market, Hamaguchi [5] studied a time-inconsistent consumption-investment problem, under general discount functions. Related research can also be found in the studies by Dybvig and Liu [6], Chen et al. [7], Wang and Li [8], Kraft and Weiss [9], and Weiss [10]. However, an investment-consumption problem considering life insurance can be traced back to Richard [11]. Richard proposes a generalized version of the Merton [2] model by incorporating insurance demand, which maximizes the expected utility of bequest and consumption. From this time on, the optimal consumption and portfolio problem involving life insurance has become a canonical problem in the field of mathematical finance and insurance actuary, e.g., Moore and Young [12], Pliska and Ye [13], Kwak and Lim [14], Ye [15], Wei et al. [16], and Zhang et al. [17]. 
However, the abovementioned works do not consider habit formation of consumption. Habit formation has found empirical support [18]. The introduction of habit formation can resolve empirical facts that seem puzzling under the assumption of a representative agent having time separable power utility. For example, Constantinides [19] and Sundaresan [20] demonstrate that models with habit formation can obtain a high equity premium with low-risk aversion. Munk [21] reveals that the utility associated with the choice of consumption at a given date is likely to depend on past choices of consumption. Li et al. [22] mention that it is not realistic to assume that instantaneous satisfaction depends on only instantaneous consumption and find that the presence of habit formation reduces the insurance coverage in the context of nonlife insurance. Therefore, a more plausible representation of preferences is to allow for habit formation.

In addition to habit formation, mortality risk and inflation risk also play important roles in the family financial asset allocation and consumption decision-making, especially for the families with only one wage earner.

The mortality risk can be hedged by life insurance, a protective tool to ensure enough remaining financial capital for dependents' future consumption if the insured dies before retirement; see the seminal papers by Richard [11], Pliska and Ye [13], and Ye [15]. However, the related works usually ignore the influence of mortality force change. Keyfitz and Caswell [23] report that the mortality force may change because of the difference in gender, nationality, or other causes and show that for developed countries, the ratio of male to female mortality ranges from about 1.10 to about 2.80 , and the largest ratio is 2-3 times the smallest, based on data. Rabitti and Borgonovo [24] studied the effect of any possible change of the mortality force on the annuity cost. In their model, the change of the mortality force is measured by introducing the constant multiplier.

Similar to the mortality risk, the inflation risk can also be hedged. Usually, one can define the stochastic price level and then introduce index bonds to hedge the inflation risk, e.g., Kwak and Lim [14], Chen et al. [7], and Wang and Li [8]. Meanwhile, Kwak and Lim [14] first considered inflation risk in the consumption-investment problem including life insurance. They show that the changes in the expected inflation rate and volatility of inflation rate can have both positive and negative impacts on the life insurance premium, and effects are considerable. In this sense, one should consider the inflation risk in the model involving life insurance.

In this study, we set up an investment, consumption, and life insurance decision problem for a wage earner subject to mortality risk and inflation risk, considering habit formation and mortality force change. To the best of our knowledge, we are the first to apply habit formation, mortality force change, and inflation risk simultaneously to a consumption-investment problem. This is the first contribution of this study. The second contribution is that we provide and prove a verification theorem and obtain closed-form expressions for the value function and the optimal strategies, by using the dynamic programming method. As the third contribution of this study, we show the influencing factors of the optimal strategy, including consumption habit, mortality force change, inflation risk, the correlation between the index bond price and stock price, income, and the relative risk aversion coefficient. Especially, we obtain the following results: the impacts of the expected inflation rate and consumption habit on the optimal strategies exhibit mutual restriction, e.g., for a given expected inflation rate, a strong (weak) habit limits (raises) the purchase of life insurance, while for a given habit strength, a high (low) expected inflation rate decreases (increases) the purchase of the life insurance; increasing mortality force raises the demand for life insurance; the effects of the other parameters (the expected growth rate of income) are also affected by consumption habit and mortality force change.

The rest of this study is organized as follows. Section 2 presents some necessary assumptions and describes the model. Section 3 obtains the analytical solution of the optimization problem of the wage earner. Section 4 analyzes the impact factors of the optimal strategies. Section 5 concludes the study.

\section{The Model}

We consider a wage earner who faces financial risk, inflation risk, and habit formulation. We assume that the investment horizon of the wage earner is $[0, T]$, where $T$ is fixed as retirement time. Trading takes place continuously, and there are no transaction costs or taxes. The uncertainty is represented by a complete probability space $(\Omega, \mathscr{F},\{\mathscr{F}(t)\}, P)$ that supports Brownian motions $W(t):=\left(W_{1}(t), W_{2}(t)\right)^{\prime}$, where $W_{1}(t)$ and $W_{2}(t)$ are mutually independent and the prime denotes the transposition of a matrix. $\{\mathscr{F}(t)\}$ is the augmentation generated by the nature filtration $\mathscr{F}(t)$ and satisfies the usual conditions, i.e., $\{\mathscr{F}(t)\}$ is right continuous and P-complete. $\mathscr{F}(t)$ represents the information available until time $t$. Assume that all the stochastic processes and random variables are well defined and adapted to $\{\mathscr{F}(t)\}$.

2.1. Financial Market and Life Insurance. Assume the wage earner can invest in an index bond, a risk-free asset, and a stock. In order to describe the inflation risk, we define the stochastic price level (cf. $[7,14,25])$ by

$$
\frac{d I(t)}{I(t)}=\mu_{I} d t+\sigma_{I} d W_{1}(t), I(0)=I_{0}
$$

where $\mu_{I}$ is the expected inflation rate, and $\sigma_{I}>0$ is the volatility of the inflation rate. The index bond (inflationlinked asset) with a constant rate of real return $\widetilde{r}$ has the price dynamics:

$$
\frac{d B(t)}{B(t)}=\tilde{r} d t+\frac{d I(t)}{I(t)}=\left(\widetilde{r}+\mu_{I}\right) d t+\sigma_{I} d W_{1}(t) .
$$

The risk-free asset has a constant rate of nominal return $r$, and its price follows the ordinary equation:

$$
\frac{d B_{0}(t)}{B_{0}(t)}=r d t \text {. }
$$


The stock price has the dynamics

$$
\frac{d S(t)}{S(t)}=\mu_{S} d t+\sigma_{S}\left(\rho_{B S} d W_{1}(t)+\sqrt{1-\rho_{B S}^{2}} d W_{2}(t)\right),
$$

where the expected return $\mu_{S}$ and volatility $\sigma_{S}>0$ are the constants, and $\rho_{B S}$ is the correlation between the index bond price and the stock price. We assume that $\left|\rho_{B S}\right|<1$ (cf. $[14,26,27])$.

Assume that the wage earner's lifetime is uncertain. Let $\tau$ denote the death time of the wage earner, which is a nonnegative random variable. Also, we assume that $\tau$ is independent of the Brownian motions $W_{1}(t)$ and $W_{2}(t)$ and has the probability density function for $\tau=s$ conditional on $\tau>t$.

$$
f(s ; t):=\lambda(s) e^{-\int_{t}^{s} \lambda(u) d u}
$$

where $\lambda(x)=\tilde{\lambda}(x)(1+\delta)$ is the force of mortality (cf. $[23,24]), \delta$ is a constant, and multiplier $1+\delta$ characters any possible change of mortality force in gender, nationality, or other causes, $\tilde{\lambda}(x)$ follows Gompertz's law as $\tilde{\lambda}(x)=1 / b e^{(x-m) / b}$, where $b>0$ and $m>0$ denote the dispersion coefficient and the modal value of life, respectively.

Assume that the wage earner purchases life insurance to hedge the mortality risk during her/his working period $[0, T]$. Specifically, the wage earner pays life insurance premium at rate $k(t)$ continuously. If the wage earner dies at time $t$, the beneficiary will receive the insurance benefit $k(t) / \zeta(t)$, where $\zeta(t)$ denotes the deterministic premium insurance ratio. It should be noted that $k(t)$ may be negative. In this case, Dybvig and Liu [6] explain that $k(t)$ resembles a term version of a life annuity since wealth (the amount is $-k(t) / \zeta(t))$ in the event of death is traded for a cash inflow while living, and Kwak and Lim [14] think of $k(t)$ as a pension annuity.

2.2. The Investment Account Dynamics and Consumption Habit. We assume that the wage earner receives a deterministic stream of income from the nonfinancial market at a rate of $Y(t)$ during the period $[0, T]$, which will be terminated at the death time of the wage earner. Let $\pi(t)=\left(\pi_{1}(t), \pi_{2}(t)\right)^{\prime}$, where $\pi_{1}(t), \pi_{2}(t)$, and $\pi_{0}(t):=1-$ $\pi_{1}(t)-\pi_{2}(t)$ denote the proportions investing in the index bond, the stock, and the risk-free asset, respectively. Let $c(t)$ denote the consumption rate for the wage earner. Meanwhile, define

$$
\begin{aligned}
\eta & :=\left(\eta_{1}, \eta_{2}\right)^{\prime}=\left(\widetilde{r}+\mu_{I}-r, \mu_{S}-r\right)^{\prime}, \\
\sum: & =\left(\begin{array}{cc}
\sigma_{I} & 0 \\
\sigma_{S} \rho_{B S} & \sigma_{S} \sqrt{1-\rho_{B S}^{2}}
\end{array}\right),
\end{aligned}
$$

where $\eta_{1}$ and $\eta_{2}>0$ are the premiums of the index bond and the stock, respectively, and the matrix $\Sigma$ is nonsingular. Then, the wealth process $X(t)$ of the wage earner is given by

$$
\left\{\begin{array}{l}
d X(t)=\left(r X(t)+\pi(t)^{\prime} \eta X(t)+Y(t)-c(t)-k(t)\right) d t+\pi(t)^{\prime} \sum X(t) d W(t) \\
X(0)=x_{0}>0
\end{array}\right.
$$

Next, we assume the wage earner develops consumption habit. Referring to Detemple and Zapatero [28], Munk [21], and $\mathrm{Li}$ et al. [22], the habit level is defined as

$$
z(t)=z_{0} e^{-\xi_{2} t}+\xi_{1} \int_{0}^{t} e^{-\xi_{2}(t-s)} c(s) d s
$$

i.e.,

$$
d z(t)=\left(\xi_{1} c(t)-\xi_{2} z(t)\right) d t
$$

where $z(0)=z_{0}>0$ is the initial habit level, $\xi_{1}>0$ is the scaling parameter, $\xi_{2}>0$ is the persistence parameter, and $\xi_{2}>\xi_{1}$. The habit level $z(t)$ represents an endogenously determined subsistence level of consumption.

Given the habit level is $z(t)$ at time $t$. If, from time $t$ onwards, the wage earner's consumption is exactly at the minimum, that is, $c(s)=z(s)$ for $s \geq t$; then, the future habit level is

$$
z(s)=z(t) e^{-\left(\xi_{2}-\xi_{1}\right)(s-t)}, \text { for } s \geq t
$$

(11) represents the wage earner's minimum consumption level. $\xi_{2}-\xi_{1}$ indicates the habit strength by determining how much the current habit level restricts future decisions. When $\xi_{2}-\xi_{1}$ is small, the habit only declines very slowly even with minimum consumption and therefore limits the wage earner more (cf. [29]).

2.3. Optimization Problem. We call $(c, k, \pi)=(\{c(t)\}$, $\{k(t)\},\{\pi(t)\})$ a strategy. A strategy $(c, k, \pi)$ is said to be admissible if $\{c(t)\},\{k(t)\}$, and $\{\pi(t)\}$ are adapted to $\{\mathscr{F}(t)\}$ and satisfy $\mathbb{E}\left[\int_{0}^{T} c(s) d s\right]<\infty, \quad \mathbb{E}\left[\int_{0}^{T} k(s) d s\right]<\infty$, and $\mathbb{E}\left[\int_{0}^{T}\|\pi(s)\|^{2} d s\right]<\infty$, where $\|\cdot\|$ denotes the Euclidean norm of a vector. Let $\Pi$ denote the set of all admissible strategies.

For an arbitrary admissible strategy $(c, k, \pi) \in \Pi$, the expected discounted utility of the wage earner at time $t$ can be expressed as 


$$
J(t, x, z)=\mathbb{E}_{t}\left[\int_{t}^{\tau \wedge T} \alpha_{1} e^{-\rho(s-t)} U(c(s)-z(s)) d s+\alpha_{2} e^{-\rho(\tau-t)} U\left(X(\tau)+\frac{k(\tau)}{\zeta(\tau)}\right) I_{\{\tau \leq T\}}+\alpha_{3} e^{-\rho(T-t)} U(X(T)) I_{\{\tau>T\}}\right]
$$

where $\mathbb{E}_{t}[\cdot]=\mathbb{E}[\cdot \mid X(t)=x, Z(t)=z], \rho$ is the time preference, $I_{\{.\}}$represents the indicator function, and $\alpha_{i}>0, i=$ $1,2,3$ are the constants with $\alpha_{1}+\alpha_{2}+\alpha_{3}=1$. In addition, $U(x)$ is the power utility function that is strictly concave, continuously differentiable, strictly increasing, and satisfies $\lim _{x \rightarrow 0}+U^{\prime}(x)=\infty, \lim _{x \rightarrow \infty} U^{\prime}(x)=0$.

In (12), the wage earner's utility is composed of three components: the utility from $c(t)-z(t)$, the part of the consumption that exceeds the minimum consumption requirement given by the habit level $z(t)$; the utility from $X(\tau)+k(\tau) / \zeta(\tau)$, the bequest as the wage earner's beneficiary in the event of premature death; and the utility from the terminal wealth $X(T)$ at retirement time. Hence, $\alpha_{1}, \alpha_{2}, \alpha_{3}$ represent the weights of the three utility components.

Now, by (5), the law of iterated expectation and some calculations (Appendix A), (12) can be transformed into

$$
J(t, x, z)=\mathbb{E}_{t}\left[\int_{t}^{T} e^{-\int_{t}^{s}(\rho+\lambda(u)) d u}\left(\alpha_{1} U(c(s)-z(s))+\alpha_{2} \lambda(s) U\left(X(s)+\frac{k(s)}{\zeta(s)}\right)\right) d s+\alpha_{3} e^{-\int_{t}^{T}(\rho+\lambda(u)) d u} U(X(T))\right] .
$$

Then, the value function is defined as

$$
V(t, x, z)=\max _{(c, k, \pi) \in \Pi(t)} J(t, x, z),
$$

where $\Pi(t)$ is the set of all admissible strategies over the time interval $[t, T]$.

\section{Solution of the Optimization Problem}

We use the dynamic programming method to solve the wage earner's optimization problem. The corresponding Hamilton-Jacobi-Bellman (HJB) equation for the value function (14) is

$$
\begin{aligned}
& V_{t}-(\rho+\lambda(t)) V+(r x+Y(t)-z) V_{x}+\left(\xi_{1}-\xi_{2}\right) z V_{z}+\max _{(c, k, \pi) \in \Pi(t)}\left\{\alpha_{1} U(c-z)-(c-z) V_{x}+\xi_{1}(c-z) V_{z}\right. \\
& \left.\quad+\alpha_{2} \lambda(t) U\left(x+\frac{k}{\zeta(t)}\right)-k V_{x}+\pi^{\prime} \eta x V_{x}+\frac{1}{2} \pi^{\prime} \Sigma \Sigma^{\prime} \pi x^{2} V_{x x}\right\}
\end{aligned}
$$

with the boundary condition $V(T, x, z)=\alpha_{3} U(x)$.

For convenience, we assume that wage earner exhibits the power utility function, i.e., $U(x)=x^{1-\gamma} / 1-\gamma$, where $\gamma(\gamma>0, \gamma \neq 1)$ is the relative risk aversion coefficient. Next, we try to find explicit solutions to the problem. We first construct a solution to HJB (15) and then derive the solution of (14).
Theorem 1. A solution to $H J B$ equation (15) with the boundary condition $\widetilde{V}(T, x, z)=\alpha_{3} U(x)$ is given by

$$
\widetilde{V}(t, x, z)=\frac{1}{1-\gamma} f(t)(x-g(t) z+h(t))^{1-\gamma} .
$$

The candidate optimal consumption and life insurance premium rates are given by

$$
\begin{aligned}
c^{*}(t) & =z^{*}(t)+\frac{\alpha_{1}^{1 / \gamma}\left(X^{*}(t)-g(t) z^{*}(t)+h(t)\right)}{\left(f(t)\left(1+\xi_{1} g(t)\right)\right)^{1 / \gamma}}, \\
k^{*}(t) & =\left(\frac{\alpha_{2} \lambda(t)}{f(t)}\right)^{1 / \gamma} \zeta(t)^{1-1 / \gamma}\left(X^{*}(t)-g(t) z^{*}(t)+h(t)\right)-X^{*}(t) \zeta(t) .
\end{aligned}
$$

The candidate optimal proportion of wealth invested in the risky assets is

$$
\pi^{*}(t)=\frac{1}{\gamma}\left(\Sigma \Sigma^{\prime}\right)^{-1} \eta \frac{X^{*}(t)-g(t) z^{*}(t)+h(t)}{X^{*}(t)}
$$


that is, the candidate optimal proportions invested in the index bond and stock are given by

$\pi_{1}^{*}(t)=\frac{1}{\gamma \sigma_{I}\left(1-\rho_{B S}^{2}\right)}\left(\frac{\eta_{1}}{\sigma_{I}}-\rho_{B S} \frac{\eta_{2}}{\sigma_{S}}\right) \frac{X^{*}(t)-g(t) z^{*}(t)+h(t)}{X^{*}(t)}$,

$\pi_{2}^{*}(t)=\frac{1}{\gamma \sigma_{S}\left(1-\rho_{B S}^{2}\right)}\left(\frac{\eta_{2}}{\sigma_{S}}-\rho_{B S} \frac{\eta_{1}}{\sigma_{I}}\right) \frac{X^{*}(t)-g(t) z^{*}(t)+h(t)}{X^{*}(t)}$,

where $\left\{X^{*}(t)\right\}$ and $\left\{z^{*}(t)\right\}$ are the wealth process and habit level corresponding to the candidate optimal strategy $\left(c^{*}, k^{*}, \pi^{*}\right)$, respectively, and

$$
\begin{aligned}
f(t) & =\tilde{f}(t)^{\gamma}, \\
\tilde{f}(t) & =\alpha_{3}^{1 / \gamma} e^{-\int_{t}^{T} f_{1}(u) d u}+\int_{t}^{T} f_{2}(s) e^{-\int_{t}^{s} f_{1}(u) d u} d s \\
f_{1}(t) & =r+\frac{\rho-r}{\gamma}-\frac{1-\gamma}{2 \gamma^{2}} \eta^{\prime}\left(\Sigma \Sigma^{\prime}\right)^{-1} \eta+\frac{1}{\gamma}(\lambda(t)-(1-\gamma) \zeta(t)), \\
f_{2}(t) & =\alpha_{1}^{1 / \gamma}\left(1+\xi_{1} g(t)\right)^{1-1 / \gamma}+\left(\alpha_{2} \lambda(t)\right)^{1 / \gamma} \zeta(t)^{1-1 / \gamma} \\
g(t) & =\int_{t}^{T} e^{-\int_{t}^{s}\left(\zeta(u)+r+\xi_{2}-\xi_{1}\right) d u} d s \\
h(t) & =\int_{t}^{T} Y(s) e^{-\int_{t}^{s}(\zeta(u)+r) d u} d s
\end{aligned}
$$

Proof. See Appendix B.

The following theorem verifies that a solution of the HJB equation (15) is indeed a solution of problem (14).

Theorem 2. For the optimization problem (14) of the wage earner, if $\widetilde{V}(t, x, z)$ is a solution of HJB equation (15) with the boundary condition $\widetilde{V}(T, x, z)=\alpha_{3} U(x)$, then the value function is $V(t, x, z)=\widetilde{V}(t, x, z)$, and the optimal strategies are given by (17), (18), (20), and (21).

Proof. See Appendix C.

Remark 1. In equations (16)-(21), $g(t) z^{*}(t)$ can be regard as the consumption habit buffer, representing the costs of ensuring that consumption exceeds the habit level (cf. [29]), and $h(t)$ is known as the human capital, which is the discounted value of the future income stream $([7,30,31])$ with the discount rate $\zeta(t)+r$ in terms of considering the premium insurance ratio. From (17) and (18), we can see that the consumption habit buffer has a negative contribution to the value function, the optimal consumption, and life insurance premium rates, while the human capital has a positive one. These are the same with intuition.

Remark 2. In (24), we assume $r+\rho-r / \gamma-1-\gamma /$ $2 \gamma^{2} \eta^{\prime}\left(\Sigma \Sigma^{\prime}\right)^{-1} \eta>0([2,14])$. In addition, we observe that $f_{1}(t)$ has an important role because the value function, the optimal consumption, and life insurance premium rates are affected by inflation risk through $f_{1}(t)$.

Remark 3. From (20), the proportion of investment in the index bond can be divided into two parts, i.e., $\eta_{1}\left(X^{*}(t)-\right.$ $\left.g(t) z^{*}(t)+h(t)\right) / \gamma \sigma_{I}^{2}\left(1-\rho_{B S}^{2}\right) X^{*}(t)$ and $-\rho_{B S} \eta_{2}\left(X^{*}(t)-\right.$ $\left.g(t) z^{*}(t)+h(t)\right) / \gamma \sigma_{I} \sigma_{S}\left(1-\rho_{B S}^{2}\right) X^{*}(t)$. The first part is proportional to the premium of the index bond and reflects investment demand. Specifically, $\eta_{1}>0(<0)$ means more (less) investment in the index bond. The second part includes $\rho_{B S} \eta_{2}$, exhibits the covariance structure, and reflects diversification demand. $\rho_{B S}>0(<0)$ means less (more) investment in the index bond due to more (less) diversification demand. Similarly, from (21), we see that $\rho_{B S} \eta_{1}>0(<0)$ means less (more) investment in the stock because of more (less) diversification demand. Meanwhile, if $\rho_{B S}=0, z_{0}=\xi_{1}=0, Y(t)=0$ in (21), i.e., the stock is free from the inflation risk, and there are no habit and labor income; then, (21) degenerates to a Merton-type strategy ([2]).

\section{Numerical Illustrations}

In this section, we present several numerical examples to highlight our findings. We mainly focus on the effects of consumption habit, mortality force change, inflation risk, the correlation between the index bond price and the stock price, income, and the relative risk aversion coefficient on the optimal strategies. For simplicity, we assume $\zeta(t)=\lambda(t)$, $\alpha_{1}=\alpha_{2}=\alpha_{3}=1 / 3$ (cf. $\left.[14,16]\right), Y(t)=y_{0} e^{\mu_{Y} t}\left(y_{0}\right.$ is the constant initial income level and $\mu_{Y}$ is the constant expected growth rate of income), and use the expected total available capital, $\mathbb{E}\left[X^{*}(t)-g(t) z^{*}(t)+h(t)\right], \quad$ in place of $X^{*}(t)-g(t) z^{*}(t)+h(t)$. Taking expectation on both sides of equation (C.3) in Appendix C, we get

$$
\mathbb{E}\left[X^{*}(t)-g(t) z^{*}(t)+h(t)\right]=\left(x_{0}-g(0) z_{0}+h(0)\right) \exp \left\{\left(r+\frac{1}{\gamma} \eta^{\prime}\left(\Sigma \Sigma^{\prime}\right)^{-1} \eta\right) t+\int_{0}^{t}\left(\zeta(u)-\frac{f_{2}(u)}{\widetilde{f}(u)}\right) d u\right\} .
$$


From (10), we can derive (Appendix D)

$$
\mathbb{E}\left[z^{*}(t)\right]=z_{0} e^{-\left(\xi_{2}-\xi_{1}\right) t}+\xi_{1} \alpha_{1}^{1 / \gamma} \int_{0}^{t} e^{-\left(\xi_{2}-\xi_{1}\right)(t-u)} \frac{\left.\mathbb{E}] X^{*}(u)-g(u) z^{*}(u)+h(u)\right]}{\widetilde{f}(u)\left(1+\xi_{1} g(u)\right)^{1 / \gamma}} d u
$$

Based on (28) and (29), we can get $\mathbb{E}\left[X^{*}(t)\right]$ and then the expected values of $c^{*}(t), k^{*}(t), \pi_{1}(t) X^{*}(t)$, and $\pi_{2}(t) X^{*}(t)$. Afterward, the terms of the consumption, the life insurance premium, and the amounts invested in the index bond and stock represent their expectations, respectively, i.e., $\mathbb{E}\left[c^{*}(t)\right], \mathbb{E}\left[k^{*}(t)\right], \mathbb{E}\left[\pi_{1}(t) X^{*}(t)\right], \quad$ and $\mathbb{E}\left[\pi_{2}(t) X^{*}(t)\right]$. Meanwhile, throughout this section, unless otherwise states, other parameters are assumed as follows (cf. $[14-16,22])$ : $T=30, \rho=0.07, \mu_{I}=0.023, \sigma_{I}=0.05, \widetilde{r}=0.02, r=0.04$, $\mu_{S}=0.08, \sigma_{S}=0.2, \rho_{B S}=-0.07, b=9.5, \quad m=51.3, x_{0}=$ $10, y_{0}=4, \mu_{Y}=0.04, \xi_{1}=0.1, \xi_{2}=0.174, \quad z_{0}=0.253, \gamma=$ $3, \delta=1.5$.

4.1. Effects of Inflation Risk and Consumption Habit. Figures 1(a) and 1(b) show that increasing the expected inflation rate raises the amounts invested in the index bond and stock; especially, the index bond is more sensitive. Meanwhile, for a given expected inflation rate, increasing habit strength $\left(\xi_{1}\right)$ reduces the amounts invested in risk assets, and when the expected inflation rate increases, the role of habit strength is more remarkable. Figure 1(c) shows the following results. (i) For a small expected inflation rate, a weak habit ( $\xi_{1}$ is small, seeing the black solid line) means that the consumption decreases over time, while a strong habit ( $\xi_{1}$ is high, seeing the black dashed line) means that the consumption increases over time; for a high expected inflation rate, the consumption increases over time, and a strong habit corresponds to rapid consumption growth. (ii) For a given habit strength (given $\xi_{1}$ ), the increase of the expected inflation rate reduces the demand for consumption, which means that the individual prefers the high return of the index bond rather than current consumption.

Figure 1(d) shows that for a given expected inflation rate, a strong (weak) habit limits (raises) the purchase of life insurance, while for a given habit strength, a high (low) expected inflation rate decreases (increases) the purchase of the life insurance.

In a word, the above conclusion shows that the impacts of the expected inflation rate and consumption habit on the optimal strategies are not independent, but mutual restraint.

However, from Figure 2, we observe that the volatility of the inflation rate has a little effect on stock investment, consumption, and life insurance purchase, but great influence on the holding for the index bond. This implies that between the consumption habit and the volatility of the inflation rate, the former affects the stock, consumption, and life insurance purchase more. Meanwhile, the impact of inflation rate volatility on the index bond holding is subject to consumption habit. Figure 2(a) shows that a high (low) volatility of the inflation rate means a low (high) holding for the index bond, and for given $\sigma_{I}$, habit consumption lowers investment in the index bond.

4.2. The Effects of Inflation Risk and Mortality Force Change. From Figure 3, we can observe that the effects of the expected inflation rate on the optimal strategies are affected by mortality force. Figures 3(a)-3(c) show that increasing the mortality force will weaken the impact of the expected inflation rate, but when the expected inflation rate decreases, this trend becomes weak. Figure 3(d) shows that for given $\delta$, the higher the expected inflation rate, the lower the demand for life insurance. Meanwhile, for a low (high) expected inflation rate, increasing the mortality force will foster (lower) the demand for life insurance.

Figure 4(a) shows that investment in the index bond is mainly affected by the volatility of the inflation rate, and high (low) volatility of the inflation rate will decrease (increase) investment in the index bond as shown in Figure 2(a). For given $\sigma_{I}$, increasing mortality force will lower investment in the index bond. However, with the increase of $\sigma_{I}$, the effects of mortality force change and $\sigma_{I}$ on the index bond are all weakened. Figures 4(b) and 4(c) show that the inflation rate volatility and mortality force change have a little effect on consumption and stock holding. However, Figure 4(d) shows that the life insurance purchase is mainly affected by mortality force change, and increasing mortality force will raise the demand for life insurance.

These results imply that in a model involving life insurance and inflation risk, it is necessary to consider mortality force change.

4.3. Effects of Other Parameters. In this subsection, we study the effects of the correlation between the index bond price and the stock price, the wage earner's income, and the relative risk aversion coefficient on the optimal strategies. For simplicity but without loss of generality, we focus on the analysis at time $T / 2$.

Figure 5 shows that the effects of the correlation between the index bond price and the stock price on the optimal strategies, under different $\xi_{1}$ and $\delta$. We observe that for given $\xi_{1}$ and $\delta$, when $\rho_{B S}$ increases, the amount invested in the index bond decreases (Figure 5(a)), the amount invested in the stock first decreases and then increases (Figure 5(b)), the consumption decreases (Figure 5(c)), and the demand for life insurance increases (Figure 5(d)).

Figure 6 shows that the effects of the wage earner's income on the optimal strategies, under different $\xi_{1}$ and $\delta$. For given $\xi_{1}$ and $\delta$, the amounts invested in risky assets, the consumption, and the demand for life insurance all increase 


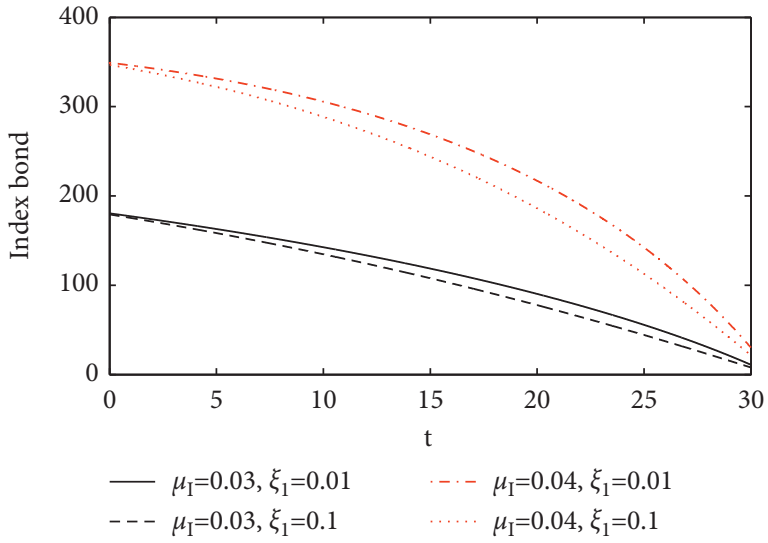

(a)

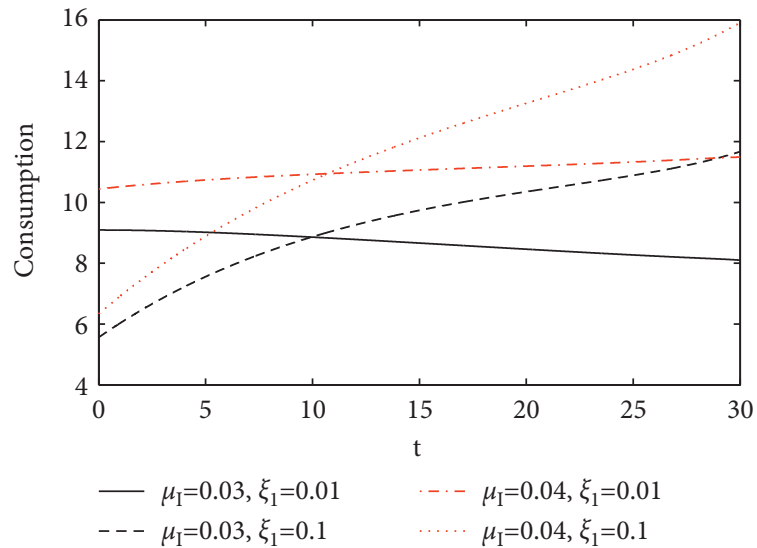

(c)

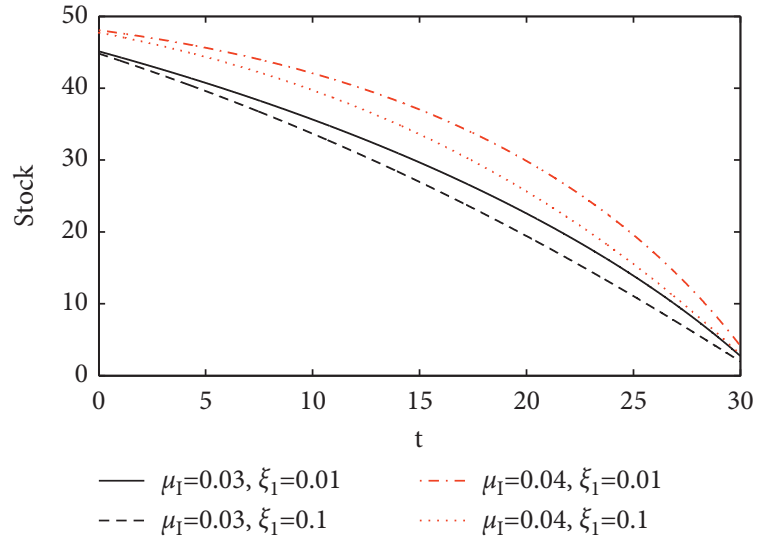

(b)

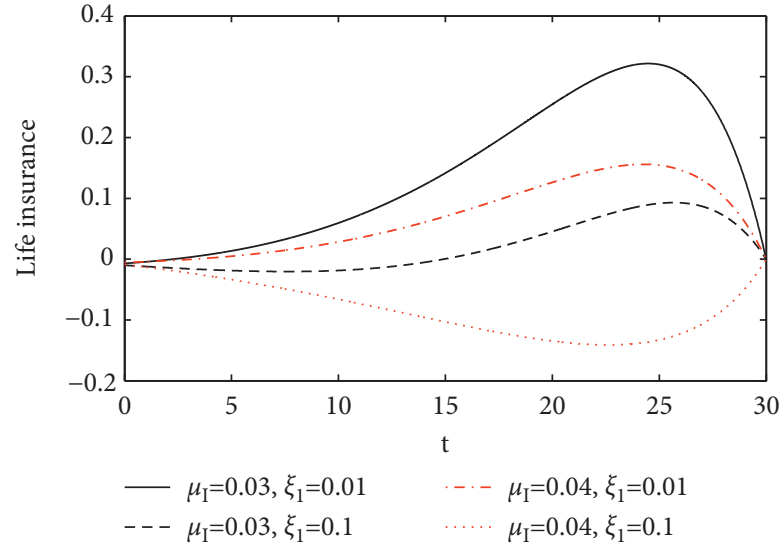

(d)

Figure 1: The effects of the expected inflation rate and consumption habit on the optimal strategies.

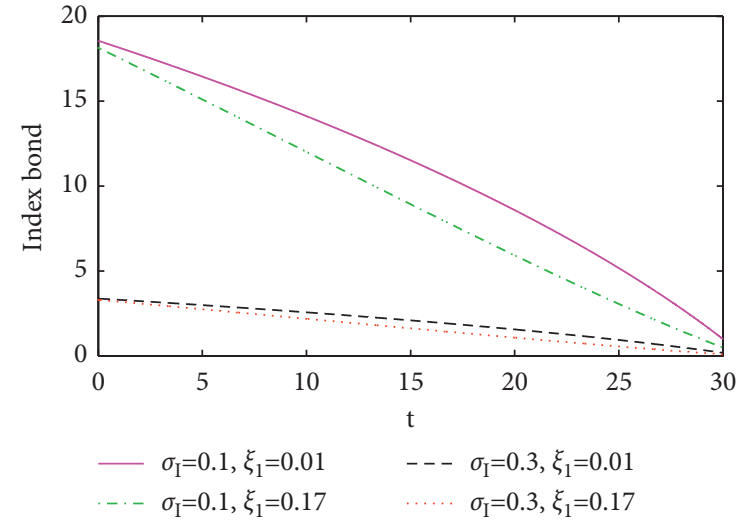

(a)

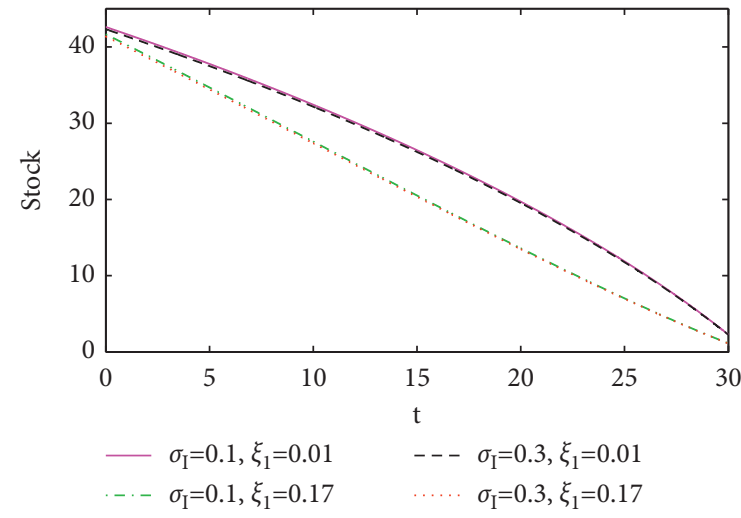

(b)

Figure 2: Continued. 


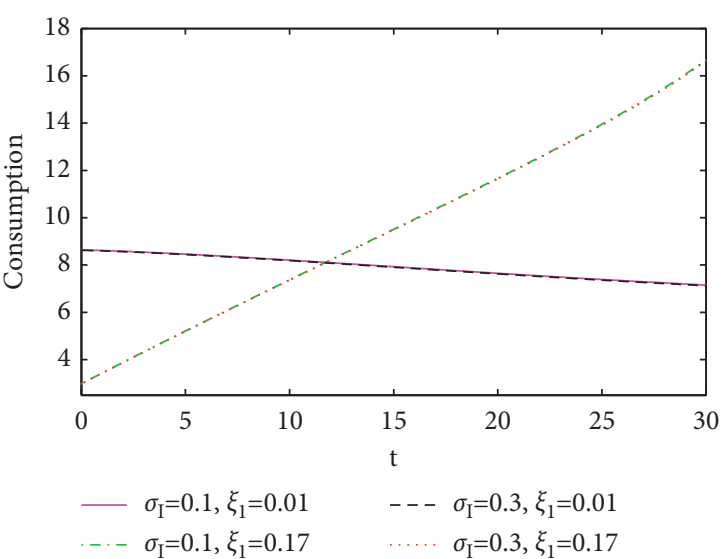

(c)

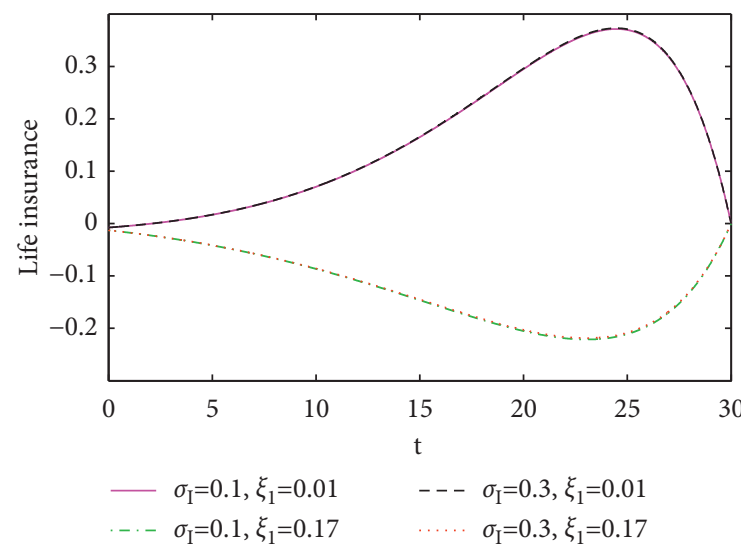

(d)

FIGURE 2: The effects of the inflation rate volatility and consumption habit on the optimal strategies.

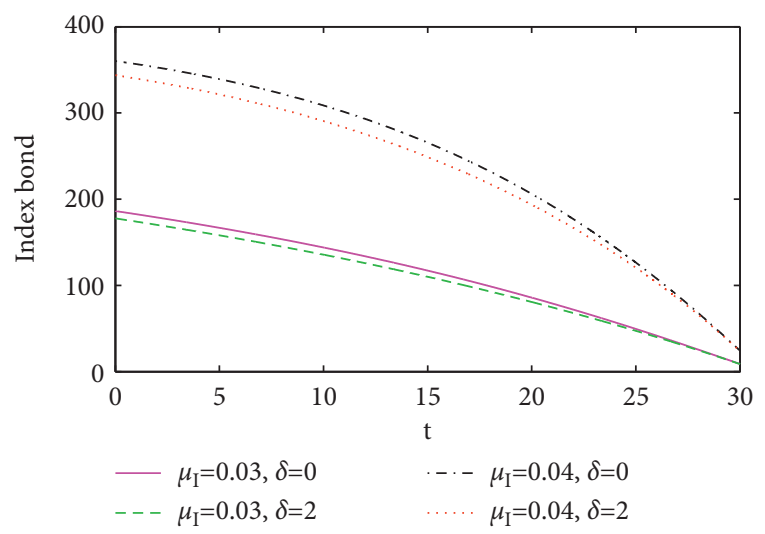

(a)

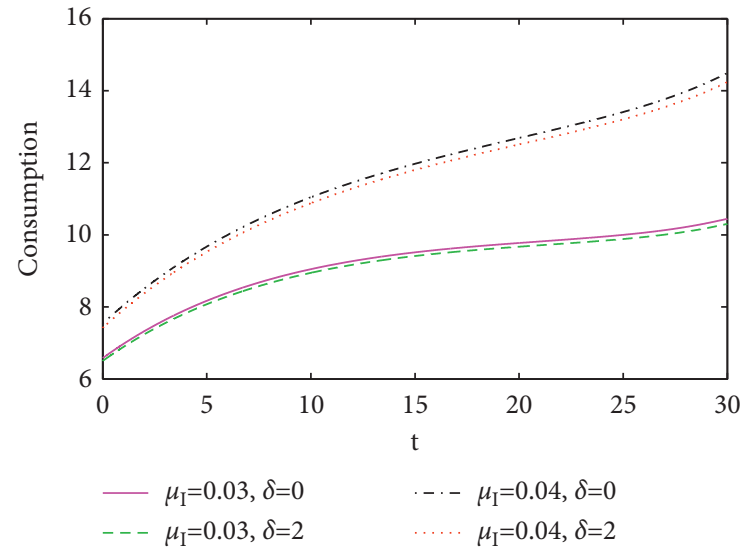

(c)

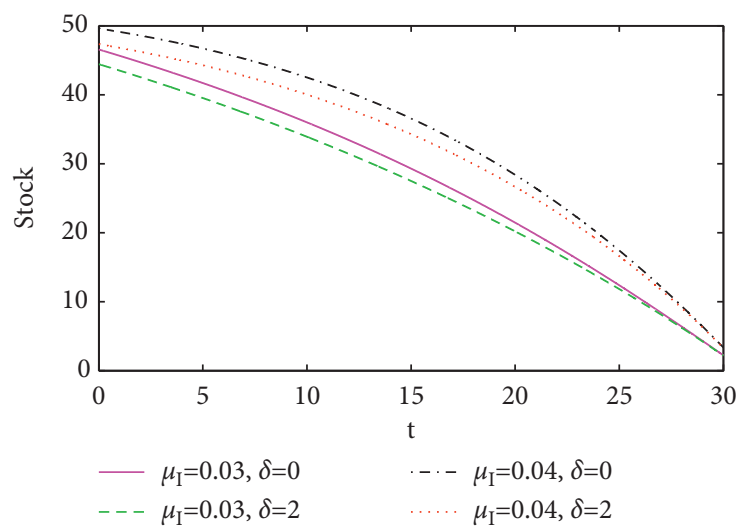

(b)

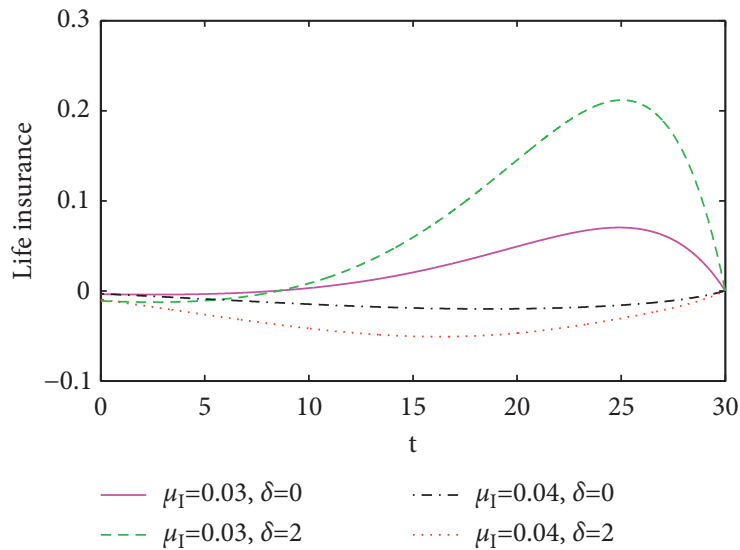

(d)

FIGURE 3: The effects of the expected inflation rate and mortality force change on the optimal strategies.

with the expected growth rate of income. These results are consistent with our intuition.

Figure 7 shows that the effects of the relative risk aversion coefficient on the optimal strategies, under different $\xi_{1}$ and $\delta$. For given $\xi_{1}$ and $\delta$, when the relative risk aversion coefficient increases, the amounts invested in risky assets and the consumption decrease, and the demand for life insurance increases. However, with the increase of $\gamma$, its impacts on the optimal strategies tend to be steady. 


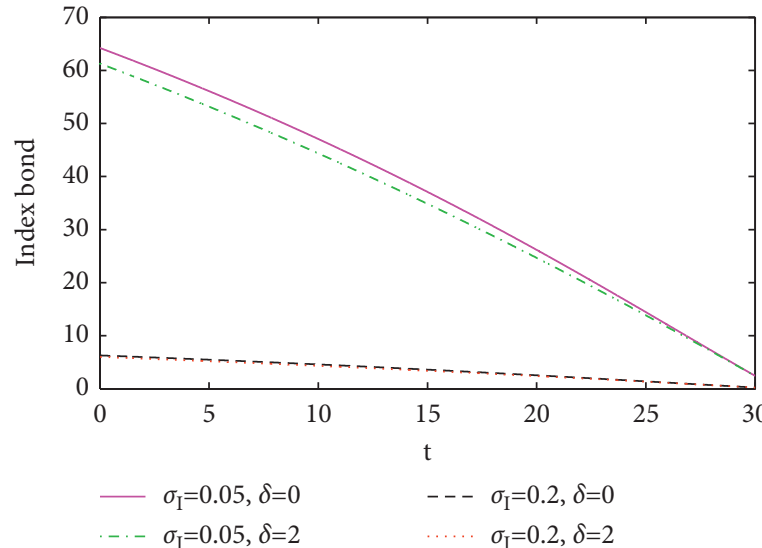

(a)

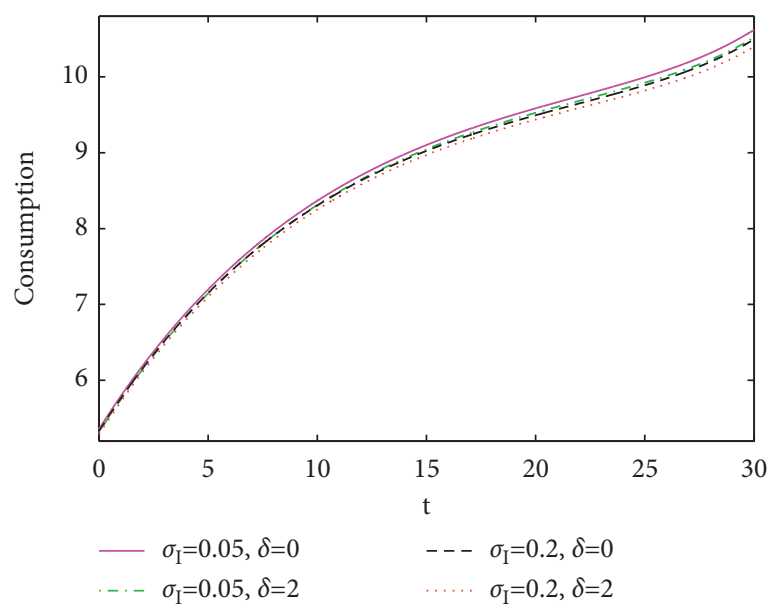

(c)

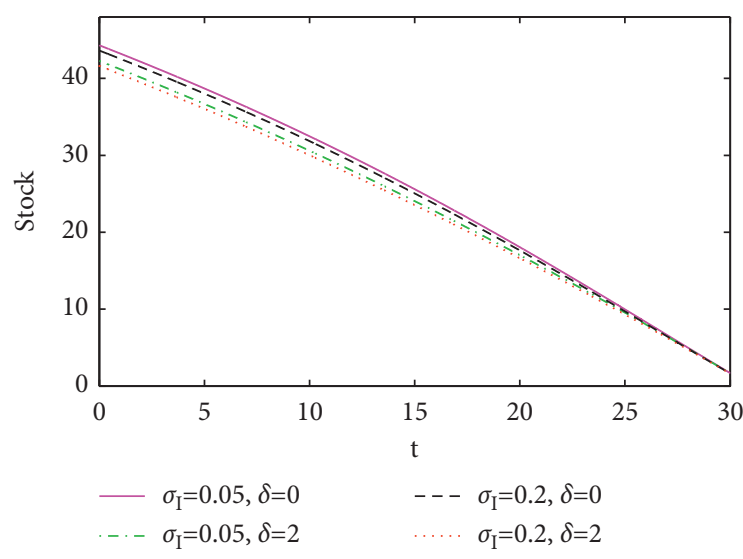

(b)

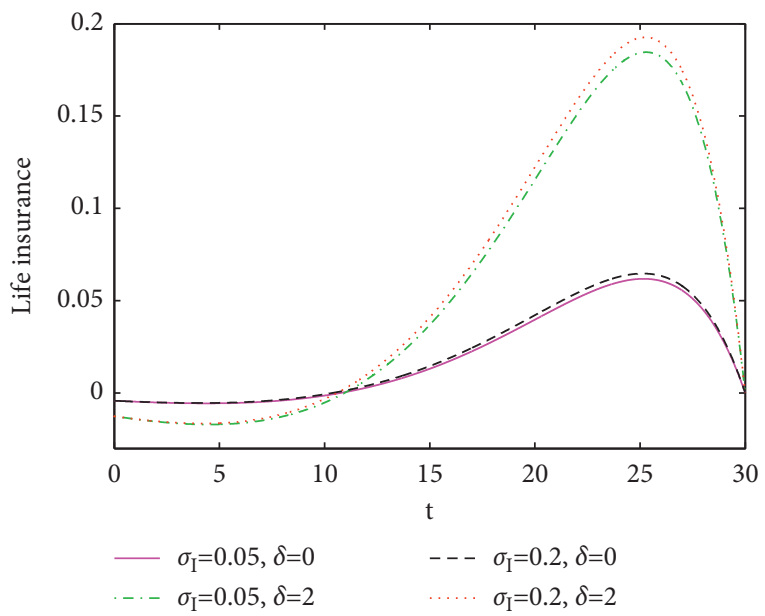

(d)

FIGURE 4: The effects of the inflation rate volatility and mortality force change on the optimal strategies.

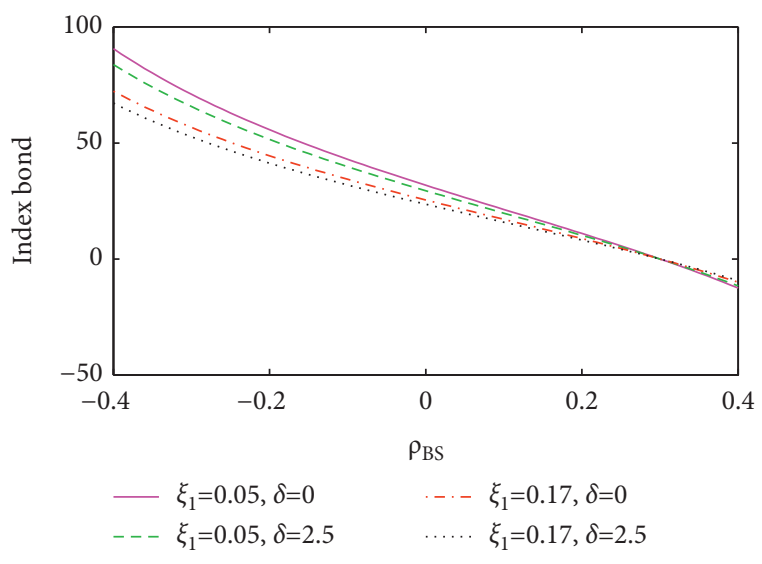

(a)

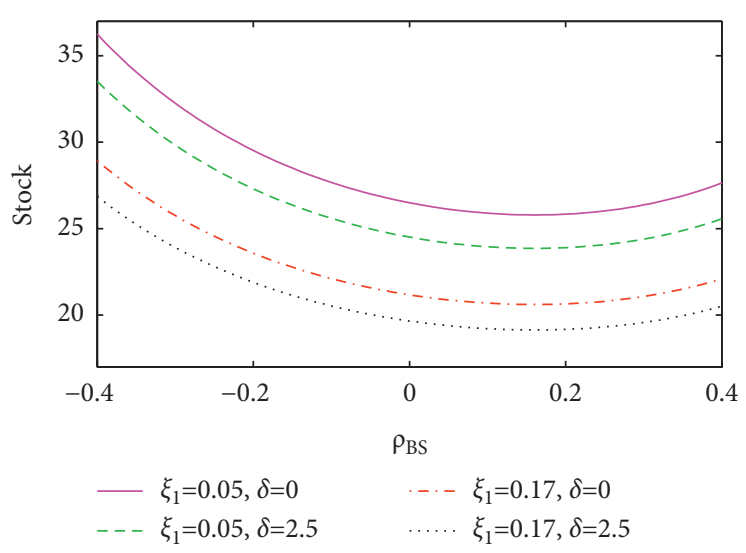

(b)

FIGURE 5: Continued. 


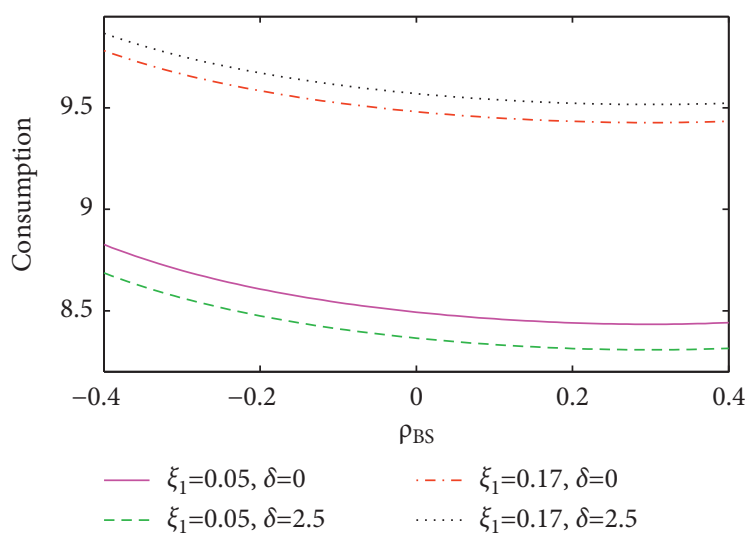

(c)

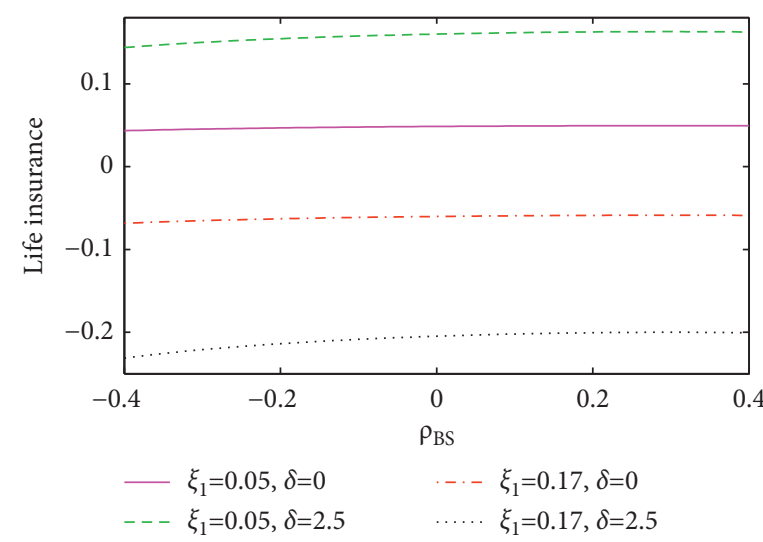

(d)

Figure 5: The effects of the correlation between the index bond and stock prices on the optimal strategies.

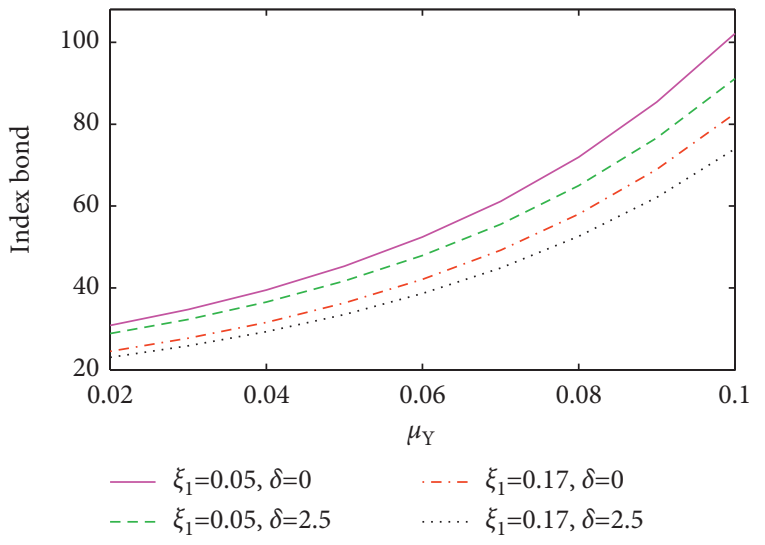

(a)

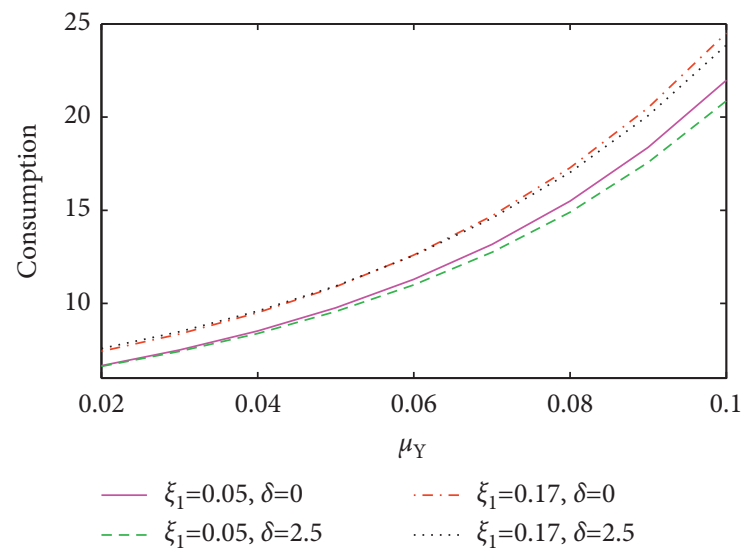

(c)

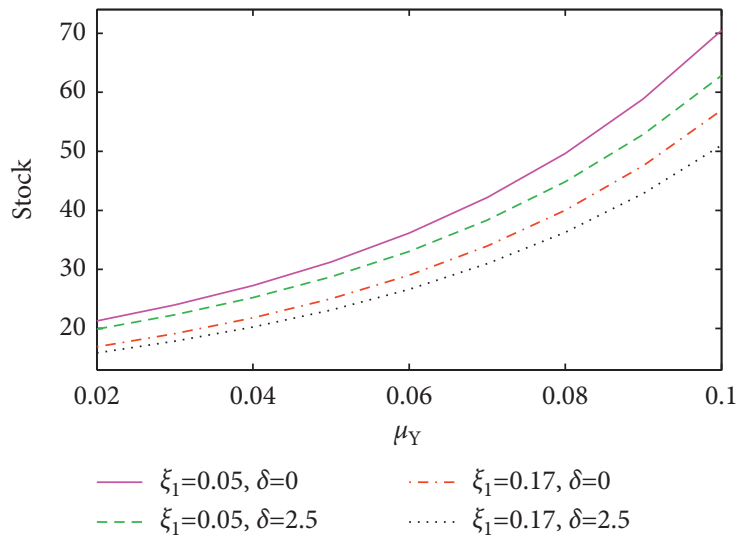

(b)

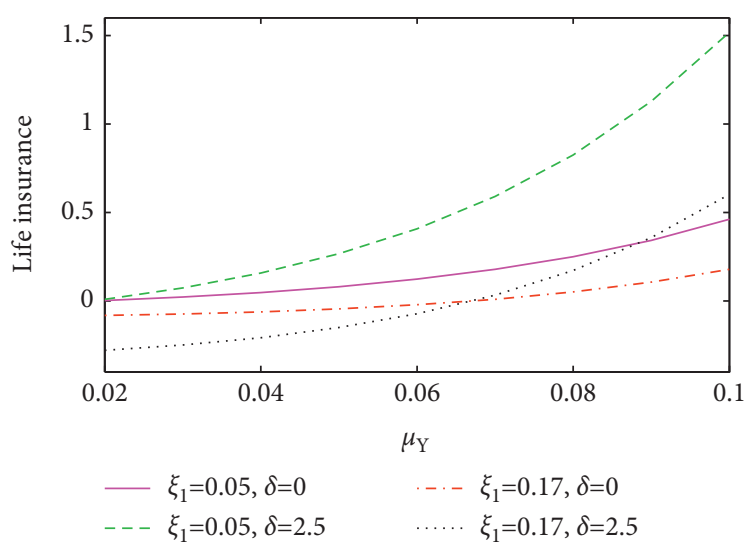

(d)

FIgURE 6: The effects of the expected growth rate of income on the optimal strategies.

From Figures 5-7, we notice that the effects of the correlation between the index bond and stock prices, income, and relative risk aversion coefficient on the optimal strategies are also affected by consumption habit and mortality force change. These further show that it is necessary to consider consumption habit and mortality force change in a problem involving the investment-consumption problem and life insurance. 


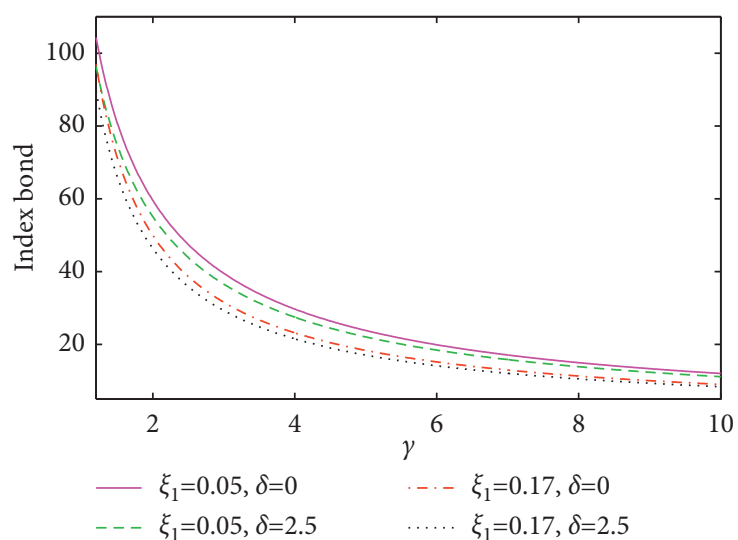

(a)

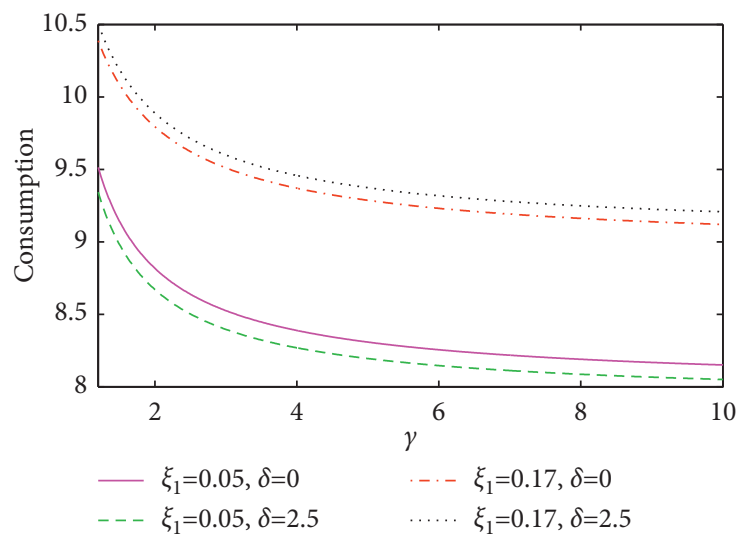

(c)

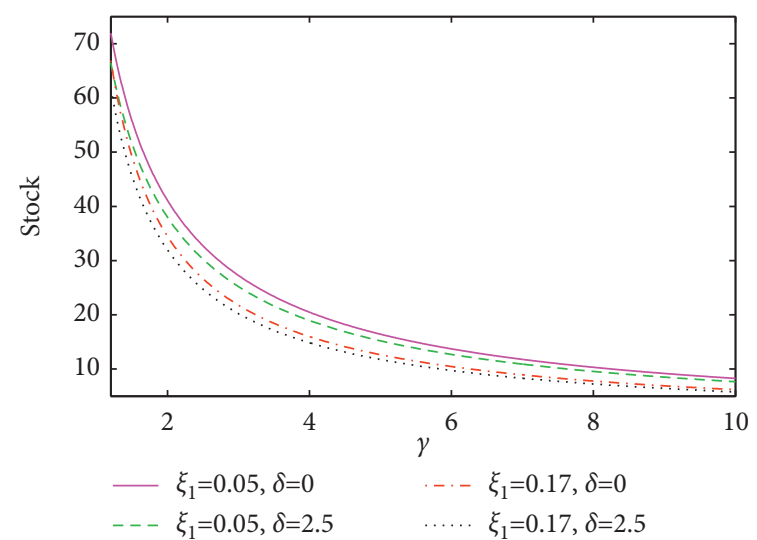

(b)

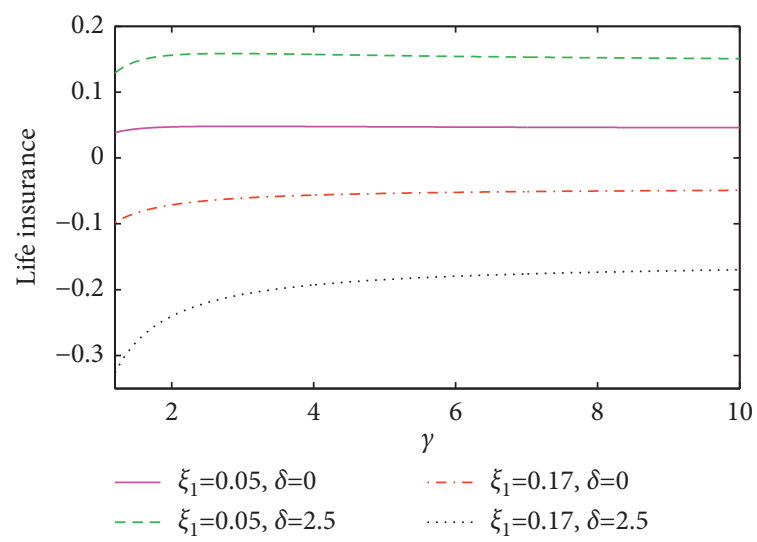

(d)

FIgURE 7: The effects of the relative risk aversion coefficient on the optimal strategies.

\section{Conclusion}

In this study, we have constructed an investment, consumption, and life insurance model for a wage earner who considers habit formation, mortality risk, and inflation risk. The wage earner consumes his/her income, invests his/her wealth in a risk-free asset, an index bond, and a stock, and purchases life insurance. The goal is to maximize the expected utility of consumption, bequest, and terminal wealth, where the utility of consumption comes from the part of the consumption that exceeds a minimum consumption requirement given by the habit level. Meanwhile, we consider a possible change of the mortality force in gender, nationality, or other causes. As theoretical results, we provide and prove a verification theorem and obtain the value function and the optimal strategies. As numerical examples, we demonstrate the effects of consumption habit, mortality force change, inflation risk, the correlation between the index bond and stock prices, income, and the relative risk aversion coefficient on the optimal strategies. The results show that consumption habit and mortality force change play important roles in the wage earner's financial behaviors, which implies that it is necessary to consider them in a problem involving consumption, investment, and life insurance.

There are some possible extensions of our model. First, our model considers only one wage earner, and in future, we can extend it to comprise two wage earners as reported in Wei et al. [16]. Second, this study assumes that the wage earner's income is deterministic, but not stochastic, aiming to obtain a simpler and explicit result, highlighting the roles of habit formation and the mortality force change. In future research, we may consider income risk. Third, one may introduce a hyperbolic discounting factor to capture the time-inconsistent preference of a wage earner. These more realistic considerations would make the model more complex and difficult to solve. 


\section{Appendix}

\section{A. The Derivation Process of (13)}

By (5) and the law of iterated expectation, we get

$$
\begin{aligned}
& \mathbb{E}_{t}\left[\int_{t}^{\tau \wedge T} e^{-\rho(s-t)} U(c(s)-z(s)) d s\right]=\int_{t}^{\infty} \mathbb{E}_{t}\left[\int_{t}^{u \wedge T} e^{-\rho(s-t)} U(c(s)-z(s)) d s\right] f(u ; t) d u \\
&= \mathbb{E}_{t}\left[\int_{t}^{T}\left(\int_{t}^{u} e^{-\rho(s-t)} U(c(s)-z(s)) d s\right) f(u ; t) d u\right]+\mathbb{E}_{t}\left[\int_{T}^{\infty}\left(\int_{t}^{T} e^{-\rho(s-t)} U(c(s)-z(s)) d s\right) f(u ; t) d u\right] \\
&= \mathbb{E}_{t}\left[\int_{t}^{T}\left(e^{-\rho(s-t)} U(c(s)-z(s))\right)\left(\int_{s}^{T} f(u ; t) d u\right) d s\right]+\mathbb{E}_{t}\left[\left(\int_{t}^{T} e^{-\rho(s-t)} U(c(s)-z(s)) d s\right)\left(\int_{T}^{\infty} f(u ; t) d u\right)\right] \\
&= \mathbb{E}_{t}\left[\int_{t}^{T} e^{-\int_{t}^{s}(\rho+\lambda(u)) d u} U(c(s)-z(s)) d s\right], \\
& \mathbb{E}_{t}\left[e^{-\rho(\tau-t)} U\left(X(\tau)+\frac{k(\tau)}{\zeta(\tau)}\right) I_{\{\tau \leq T\}}\right]=\int_{t}^{T} \mathbb{E}_{t}\left[e^{-\rho(s-t)} U\left(X(s)+\frac{k(s)}{\zeta(s)}\right)\right] f(s ; t) d s \\
&=\mathbb{E}_{t}\left[\int_{t}^{T} e^{-\int_{t}^{s}(\rho+\lambda(u)) d u} \lambda(s) U\left(X(s)+\frac{k(s)}{\zeta(s)}\right) d s\right], \\
& \mathbb{E}_{t}\left[e^{-\rho(T-t)} U(X(T)) I_{\{\tau>T\}}\right]=e^{-\rho(T-t)} \int_{T}^{\infty} \mathbb{E}_{t}[U(X(T))] f(u ; t) d u=e^{-\int_{t}^{T}(\rho+\lambda(u)) d u} \mathbb{E}_{t}[U(X(T))] .
\end{aligned}
$$

From (A.1)-(A.3), we can obtain (13).

$$
\pi^{*}=-\left(\Sigma \Sigma^{\prime}\right)^{-1} \eta \frac{1}{x} \frac{\widetilde{V}_{x}}{\widetilde{V}_{x x}} .
$$

\section{B. Proof of Theorem 1}

Substituting (B.1)-(B.3) into (15) yields

Suppose that $\widetilde{V}(t, x, z)$ is a solution of HJB equation (15) satisfying $\widetilde{V}_{z}<0, \widetilde{V}_{x}>0$, and $\widetilde{V}_{x x}<0$, then the first-order optimal conditions are

$$
\begin{gathered}
c^{*}=z+\alpha_{1}^{1 / \gamma}\left(1-\xi_{1} \frac{\widetilde{V}_{z}}{\widetilde{V}_{x}}\right)^{-1 / \gamma} \widetilde{V}_{x}^{-1 / \gamma}, \\
k^{*}=\left(\alpha_{2} \lambda(t)\right)^{1 / \gamma} \zeta(t)^{1-1 / \gamma} \widetilde{V}^{-1 / \gamma}-x \zeta(t),
\end{gathered}
$$

$$
\begin{gathered}
\widetilde{V}_{t}-(\rho+\lambda(t)) \widetilde{V}+(r x+Y(t)-z) \widetilde{V}_{x}+\left(\xi_{1}-\xi_{2}\right) z \widetilde{V}_{z}+\frac{\gamma}{1-\gamma} \alpha_{1}^{1 / \gamma}\left(1-\xi_{1} \widetilde{V}_{z}\right)^{1-1 / \gamma} \widetilde{V}_{x}^{1-1 / \gamma} \\
+\frac{\gamma}{1-\gamma}\left(\alpha_{2} \lambda(t)\right)^{1 / \gamma} \zeta(t)^{1-1 / \gamma} \widetilde{V}_{x}^{1-1 / \gamma}-x \zeta(t) \widetilde{V}_{x}-\frac{1}{2} \eta^{\prime}\left(\Sigma \Sigma^{\prime}\right)^{-1} \eta \frac{\widetilde{V}_{x}^{2}}{\widetilde{V}_{x x}}=0 .
\end{gathered}
$$

We guess that a solution of (B.4) has the form 


$$
\begin{gathered}
\tilde{V}(t, x, z)=\frac{1}{1-\gamma} f(t)(x-g(t) z+h(t))^{1-\gamma}, \\
f(T)=\alpha_{3}^{1 / \gamma}, g(T)=0, h(T)=0 .
\end{gathered}
$$

The corresponding partial derivatives of $\widetilde{V}(t, x, z)$ are

$$
\begin{aligned}
& \widetilde{V}_{t}=\frac{1}{1-\gamma} f^{\prime}(t) Q^{1-\gamma}+f(t)\left(h^{\prime}(t)-g^{\prime}(t) z\right) Q^{-\gamma}, \widetilde{V}_{x}=f(t) Q^{-\gamma}, \\
& \widetilde{V}_{z}=-f(t) g(t) Q^{-\gamma}, \widetilde{V}_{x x}=-\gamma f(t) Q^{-\gamma-1},
\end{aligned}
$$

where $Q=x-g(t) z+h(t)$. Substituting the above derivatives and $\widetilde{V}(t, x, z)$ into (B.4) yields

$$
(G(t)-\zeta(t)+r) x-\left(g^{\prime}(t)+\left(G(t)+\xi_{1}-\xi_{2}\right) g(t)+1\right) z+G(t) h(t)+h^{\prime}(t)+Y(t)=0,
$$

where

$$
\begin{aligned}
G(t)= & \frac{1}{1-\gamma} \frac{f^{\prime}(t)}{f(t)}+\frac{\gamma}{1-\gamma}\left(\alpha_{1}^{1 / \gamma}\left(1+\xi_{1} g(t)\right)^{1-1 / \gamma}+\left(\alpha_{2} \lambda(t)\right)^{1 / \gamma} \zeta(t)^{1-1 / \gamma}\right) f(t)^{-1 / \gamma} \\
& -\frac{1}{1-\gamma}(\rho+\lambda(t))+\frac{1}{2 \gamma} \eta^{\prime}\left(\Sigma \Sigma^{\prime}\right)^{-1} \eta .
\end{aligned}
$$

Then, we have the following equations:

$$
\begin{aligned}
& G(t)+\zeta(t)+r=0, \\
& g^{\prime}(t)+\left(G(t)+\xi_{1}-\xi_{2}\right) g(t)+1=0, \\
& h^{\prime}(t)+G(t) h(t)+Y(t)=0,
\end{aligned}
$$

with $f(T)=\alpha_{3}^{1 / \gamma}, g(T)=0, h(T)=0$. Solving the above equations, we obtain

$$
\begin{aligned}
f(t) & =\tilde{f}(t)^{\gamma} \\
\tilde{f}(t) & =\alpha_{3}^{1 / \gamma} e^{-\int_{t}^{T} f_{1}(u) d u}+\int_{t}^{T} f_{2}(s) e^{-\int_{t}^{s} f_{1}(u) d u} d s \\
f_{1}(t) & =r+\frac{\rho-r}{\gamma}-\frac{1-\gamma}{2 \gamma^{2}} \eta^{\prime}\left(\Sigma \Sigma^{\prime}\right)^{-1} \eta+\frac{1}{\gamma}(\lambda(t)-(1-\gamma) \zeta(t)), \\
f_{2}(t) & =\alpha_{1}^{1 / \gamma}\left(1+\xi_{1} g(t)\right)^{1-1 / \gamma}+\left(\alpha_{2} \lambda(t)\right)^{1 / \gamma} \zeta(t)^{1-1 / \gamma}, \\
g(t) & =\int_{t}^{T} e^{-\int_{t}^{s}\left(\zeta(u)+r+\xi_{2}-\xi_{1}\right) d u} d s \\
h(t) & =\int_{t}^{T} Y(s) e^{-\int_{t}^{s}(\zeta(u)+r) d u} d s .
\end{aligned}
$$


Substituting $\widetilde{V}(t, x, z)$ into (B.1)-(B.3), after some calculation, we get (17)-(21).

\section{Proof of Theorem 2}

In order to prove Theorem 2, we first introduce a lemma (cf. $[32,33])$.
Lemma 1. Assume that $\tilde{V}(t, x, z)$ is given by (16); then, for any $t \in[0, T]$,

$$
\mathbb{E}\left[\widetilde{V}^{2}\left(t, X^{*}(t), z^{*}(t)\right)\right]<\infty .
$$

Proof. Substituting (17)-(19) into (8) yields

$$
\frac{d\left(X^{*}(t)-g(t) z^{*}(t)+h(t)\right)}{X^{*}(t)-g(t) z^{*}(t)+h(t)}=\left(\zeta(t)-\frac{f_{2}(t)}{\widetilde{f}(t)}+\frac{1}{\gamma} \eta^{\prime}\left(\Sigma \Sigma^{\prime}\right)^{-1} \eta+r\right) d t+\frac{1}{\gamma} \eta^{\prime}\left(\Sigma^{\prime}\right)^{-1} d W(t)
$$

It is easy to get

$$
X^{*}(t)-g(t) z^{*}(t)+h(t)=\left(x_{0}-g(0) z_{0}+h(0)\right) \exp \left\{\int_{0}^{t} Q_{1}(u) d u+\frac{1}{\gamma} \eta^{\prime}\left(\Sigma^{\prime}\right)^{-1} W(t)\right\},
$$

where $\quad Q_{1}(t)=\zeta(t)-f_{2}(t) / \tilde{f}(t)+1 / \gamma \eta^{\prime}\left(\Sigma \Sigma^{\prime}\right)^{-1} \eta+r-$ $1 / 2 \gamma^{2} \eta^{\prime}\left(\Sigma \Sigma^{\prime}\right)^{-1} \eta t$ is a deterministic and bounded function on $[0, T]$. Substituting (C.3) into (16), since $\mathbb{E}[\exp (2(1-$ $\left.\left.\gamma) / \gamma \eta^{\prime} \quad\left(\Sigma^{\prime}\right)^{-1} W(t)\right)\right]=\exp \left(2(1-\gamma)^{2} / \gamma^{2} \eta^{\prime}\left(\Sigma \Sigma^{\prime}\right)^{-1} \eta t\right)$, we can obtain $\mathbb{E}\left[\tilde{V}^{2}\left(t, X^{*}(t), z^{*}(t)\right)\right]<\infty$.

Next, we prove Theorem 2. For convenience, we denote $\mathscr{D}:=] 0, T] \times] 0, \infty) \times] 0, \infty)$ and define the generator

$$
\mathscr{A} \widetilde{V}(t, x, z)=\widetilde{V}_{t}-(\rho+\lambda(t)) \widetilde{V}+\left(r x+\pi^{\top} \eta x+Y(t)-c-k\right) \widetilde{V}_{x}+\left(\xi_{1} c-\xi_{2} z\right) \widetilde{V}_{z}+\frac{1}{2} \pi^{\prime} \Sigma \Sigma^{\prime} \pi x^{2} \widetilde{V}_{x x}
$$

By the Dynkin formula, Lemma 1 and (15), we get

$$
\begin{aligned}
& \mathbb{E}_{t}\left[e^{-\int_{t}^{T}(\rho+\lambda(u)) d u} \widetilde{V}(T, X(T), Z(T))\right]-\widetilde{V}(t, x, z) \\
& =\mathbb{E}_{t}\left[e^{-\int_{t}^{s}(\rho+\lambda(u)) d u} \mathscr{A} \widetilde{V}(s, X(s), Z(s)) d s\right] \\
& \leq-\mathbb{E}_{t}\left[\int_{t}^{T} e^{\int_{t}^{s}(\rho+\lambda(u)) d s}\left(\alpha_{1} U(c(s)-z(s))+\alpha_{2} \lambda(s) U\left(X(s)+\frac{k(s)}{\zeta(s)}\right)\right) d s\right] .
\end{aligned}
$$

Thus, we obtain 


$$
\begin{aligned}
\tilde{V}(t, x, z) & \geq \mathbb{E}_{t}\left[\int_{t}^{T} e^{\int_{t}^{s}(\rho+\lambda(u)) d s}\left(\alpha_{1} U(c(s)-z(s))+\alpha_{2} \lambda(s) U\left(X(s)+\frac{k(s)}{\zeta(s)}\right)\right) d s+e^{-\int_{t}^{T}(\rho+\lambda(u)) d u} \widetilde{V}(T, X(T), Z(T))\right] \\
& =\mathbb{E}_{t}\left[\int_{t}^{T} e^{\int_{t}^{s}(\rho+\lambda(u)) d s}\left(\alpha_{1} U(c(s)-z(s))+\alpha_{2} \lambda(s) U\left(X(s)+\frac{k(s)}{\zeta(s)}\right)\right) d s+e^{-\int_{t}^{T}(\rho+\lambda(u)) d u} \alpha_{3} U(x)\right] .
\end{aligned}
$$

Taking the supreme w.r.t $(c, k, \pi)$ in (C.6) and combining with (14), we have

$$
\widetilde{V}(t, x, z) \geq V(t, x, z) \text { for }(t, x, z) \in \mathscr{D} \text {. }
$$

Moreover, under the strategy $\left(c^{*}, k^{*}, \pi^{*}\right)$, the inequalities in (C.5) and (C.6) become the equalities. We have

$$
\widetilde{V}(t, x, z)=\mathbb{E}_{t} \int_{t}^{T} e^{\int_{t}^{s}(\rho+\lambda(u)) d s}\left(\alpha_{1} U(c(s)-z(s))+\alpha_{2} \lambda(s) U\left(X(s)+\frac{k(s)}{\zeta(s)}\right)\right) d s+e^{-\int_{t}^{T}(\rho+\lambda(u)) d u} \widetilde{V}(T, X(T), Z(T)) \leq V(t, x, z),
$$

for all $(t, x, z) \in \mathscr{D}$. Combining (C.7) and (C.8), we get $\widetilde{V}(t, x, z)=V(t, x, z)$.

\section{The Expectation of $z^{*}(t)$}

From (10), we have

$$
d z^{*}(t)+\left(\xi_{2}-\xi_{1}\right) z^{*}(t) d t=\xi_{1}\left(c^{*}(t)-z^{*}(t)\right) d t,
$$

and thus,

$$
z^{*}(t)=z_{0} e^{-\left(\xi_{2}-\xi_{1}\right) t}+\xi_{1} \int_{0}^{t} e^{-\left(\xi_{2}-\xi_{1}\right)(t-u)}\left(c^{*}(u)-z^{*}(u)\right) d u .
$$
derive

By equation (17), we take the expectation of $z^{*}(t)$ and

$$
\mathbb{E}\left[z^{*}(t)\right]=z_{0} e^{-\left(\xi_{2}-\xi_{1}\right) t}+\xi_{1} \alpha_{1}^{1 / \gamma} \int_{0}^{t} e^{-\left(\xi_{2}-\xi_{1}\right)(t-u)} \frac{\mathbb{E}\left[X^{*}(u)-g(u) z^{*}(u)+h(u)\right]}{\tilde{f}(u)\left(1+\xi_{1} g(u)\right)^{1 / \gamma}} d u
$$

\section{Data Availability}

No data were used in this study.

\section{Conflicts of Interest}

The authors declare that they have no conflicts of interest.

\section{Acknowledgments}

This research was supported by the National Natural Science Foundation of China (71721001 and 71991474) and the State Scholarship Fund of China (202106380104).

\section{References}

[1] P. A. Samuelson, "Lifetime portfolio selection by dynamic stochastic programming," The Review of Economics and Statistics, vol. 51, no. 3, pp. 239-246, 1969.

[2] R. C. Merton, "Lifetime portfolio selection under uncertainty: the continuous-time case," The Review of Economics and Statistics, vol. 51, no. 3, pp. 247-257, 1969.

[3] Z. Zou, S. Chen, and L. Wedge, "Finite horizon consumption and portfolio decisions with stochastic hyperbolic discounting," Journal of Mathematical Economics, vol. 52, no. 5, pp. 70-80, 2014.
[4] Z. Yang, G. Liang, and C. Zhou, "Constrained portfolioconsumption strategies with uncertain parameters and borrowing costs," Mathematics and Financial Economics, vol. 13, no. 3, pp. 393-427, 2019.

[5] Y. Hamaguchi, "Time-inconsistent consumption-investment problems in incomplete markets under general discount functions," SIAM Journal on Control and Optimization, vol. 59, no. 3, pp. 2121-2146, 2021.

[6] P. H. Dybvig and H. Liu, "Lifetime consumption and investment: retirement and constrained borrowing," Journal of Economic Theory, vol. 145, no. 3, pp. 885-907, 2010.

[7] Z. Chen, Z. Li, Y. Zeng, and J. Sun, "Asset allocation under loss aversion and minimum performance constraint in a DC pension plan with inflation risk," Insurance: Mathematics and Economics, vol. 75, pp. 137-150, 2017.

[8] P. Wang and Z. Li, "Robust optimal investment strategy for an AAM of DC pension plans with stochastic interest rate and stochastic volatility," Insurance: Mathematics and Economics, vol. 80, pp. 67-83, 2018.

[9] H. Kraft and F. Weiss, "Consumption-portfolio choice with preferences for cash," Journal of Economic Dynamics and Control, vol. 98, pp. 40-59, 2019.

[10] F. Weiss, "A numerical approach to solve consumptionportfolio problems with predictability in income, stock prices, and house prices," Mathematical Methods of Operations Research, vol. 93, no. 1, pp. 1-49, 2021.

[11] S. F. Richard, "Optimal consumption, portfolio and life insurance rules for an uncertain lived individual in a continuous 
time model," Journal of Financial Economics, vol. 2, no. 2, pp. 187-203, 1975.

[12] K. S. Moore and V. R. Young, "Optimal insurance in a continuous-time model," Insurance: Mathematics and Economics, vol. 39, no. 1, pp. 47-68, 2006.

[13] S. R. Pliska and J. Ye, "Optimal life insurance purchase and consumption/investment under uncertain lifetime," Journal of Banking \& Finance, vol. 31, no. 5, pp. 1307-1319, 2007.

[14] M. Kwak and B. H. Lim, "Optimal portfolio selection with life insurance under inflation risk," Journal of Banking \& Finance, vol. 46, pp. 59-71, 2014.

[15] J. Ye, "Stochastic utilities with subsistence and satiation: optimal life insurance purchase, consumption and investment," Insurance: Mathematics and Economics, vol. 89, pp. 193-212, 2019.

[16] J. Wei, X. Cheng, Z. Jin, and H. Wang, "Optimal consumption-investment and life-insurance purchase strategy for couples with correlated lifetimes," Insurance: Mathematics and Economics, vol. 91, pp. 244-256, 2020.

[17] J. Zhang, S. Purcal, and J. Wei, "Optimal life insurance and annuity demand under hyperbolic discounting when bequests are luxury goods," Insurance: Mathematics and Economics, vol. 101, pp. 80-90, 2021.

[18] M. Browning and M. D. Collado, "Habits and heterogeneity in demands: a panel data analysis," Journal of Applied Econometrics, vol. 22, no. 3, pp. 625-640, 2007.

[19] G. M. Constantinides, "Habit formation: a resolution of the equity premium puzzle," Journal of Political Economy, vol. 98, no. 3, pp. 519-543, 1990.

[20] S. M. Sundaresan, "Intertemporally dependent preferences and the volatility of consumption and wealth," Review of Financial Studies, vol. 2, no. 1, pp. 73-89, 1989.

[21] C. Munk, "Portfolio and consumption choice with stochastic investment opportunities and habit formation in preferences," Journal of Economic Dynamics and Control, vol. 32, no. 11, pp. 3560-3589, 2008.

[22] W. Li, K. S. Tan, and P. Wei, "Demand for non-life insurance under habit formation," Insurance: Mathematics and Economics, vol. 101, pp. 28-54, 2021.

[23] N. Keyfitz and H. Caswell, Applied Mathematical Demography, Springer-Verlag, New York, NY, USA, 3rd edition, 2005.

[24] G. Rabitti and E. Borgonovo, "Is mortality or interest rate the most important risk in annuity models? a comparison of sensitivity analysis methods," Insurance: Mathematics and Economics, vol. 95, pp. 48-58, 2020.

[25] F. Mkaouar, J.-L. Prigent, and I. Abid, "Long-term investment with stochastic interest and inflation rates: the need for inflation-indexed bonds," Economic Modelling, vol. 67, pp. 228-247, 2017.

[26] A. Anari and J. Kolari, "Stock prices and inflation," Journal of Financial Research, vol. 24, no. 4, pp. 587-602, 2001.

[27] B. S. Lee, "Stock returns and inflation revisited: an evaluation of the inflation illusion hypothesis," Journal of Banking \& Finance, vol. 34, no. 6, pp. 1257-1273, 2010.

[28] J. B. Detemple and F. Zapatero, "Asset prices in an exchange economy with habit formation," Econometrica, vol. 59, no. 6, pp. 1633-1657, 1991.

[29] H. Kraft, C. Munk, and S. Wagner, "Housing habits and their implications for life-cycle consumption and investment," Review of Finance, vol. 22, no. 5, pp. 1737-1762, 2018.

[30] Z. Bodie, R. C. Merton, and W. F. Samuelson, "Labor supply flexibility and portfolio choice in a life cycle model," Journal of
Economic Dynamics and Control, vol. 16, no. 3, pp. 427-449, 1992.

[31] H. Kraft and C. Munk, "Optimal housing, consumption, and investment decisions over the life cycle," Management Science, vol. 57, no. 6, pp. 1025-1041, 2011.

[32] A. Chunxiang and Z. Li, "Optimal investment and excess-ofloss reinsurance problem with delay for an insurer under Heston's SV model," Insurance: Mathematics and Economics, vol. 61, pp. 181-196, 2015.

[33] A. Gu, X. Guo, Z. Li, and Y. Zeng, "Optimal control of excessof-loss reinsurance and investment for insurers under a cev model," Insurance: Mathematics and Economics, vol. 51, no. 3, pp. 674-684, 2012. 